\title{
Editorial
}

\section{Integrative Approaches to Safeguarding the Health and Safety of Workers}

In many regions, larger employers oversee a wide array of programs and activities to help manage the health, safety and well-being of workers. Examples of these functions include occupational safety and health programs, disability and return-to-work programs, disease management programs, worker compensation programs, employee assistance and health promotion or wellness programs, and various human resource initiatives such as work-family programs. In a recent guidance statement, however, the American College of Occupational and Environmental Medicine (ACOEM) expressed strong concerns that these programs typically operate independently of one another, thus limiting their effectiveness from both a prevention and cost perspective ${ }^{1)}$. This fragmentation is perhaps most apparent in the gulf that has existed historically between worksite health promotion or wellness programs that focus on personal lifestyle and behavioral risks, and health protection programs that deal with occupational exposures.

Concern about fragmentation of workplace health programs is not new. Two decades ago DeJoy and others ${ }^{2,3)}$ argued for ecological or systems approaches to occupational safety and health that acknowledge the multi-causal nature of injury and illness among workers, and deliver packages of interventions that address both personal and occupational risk factors in a coordinated way. The occupational safety and health field is now responding to this challenge.

National health organizations in the United States have joined with ACOEM in efforts to dissolve barriers among distinct environmental, health, and safety programs and policies in the workplace. In its 2005 report, Integrating Employee Health ${ }^{4}$, the Institute of Medicine issued recommendations for the design and conduct of a comprehensive, integrated health and safety program in a Federal agency, which serves also as a model for industry at large. More specific guidance for the development of integrated health promotion and health protection programs in the workplace was issued by the Labor Occupational Health Program at the University of California, Berkeley in $2010^{5}$, and also by Harvard University in $2012^{6}$. In 2011 the National Institute for Occupational Safety and Health (NIOSH) coined the expression Total Worker Health ${ }^{\mathrm{TM}}$ in reference to integrated workplace prevention strategies, and re-titled its research program on this topic to the Total Worker Health $^{\mathrm{TM}}$ Program ${ }^{7,8)}$. Additionally, support for NIOSH intramural research in Total Worker Health ${ }^{\mathrm{TM}}$ was increased and, on the extramural side, a fourth Center of Excellence to Promote a Healthier Workforce was funded ${ }^{7,8)}$.

What's behind this fresh enthusiasm for integrated prevention strategies in occupational safety and health? As noted, there has been long-standing interest in the integration of worksite health promotion and health protection programs. But, in my view, the present focus on integration is more the product of two converging developments. First, and perhaps most important, is growing appreciation that efforts to protect the health and safety of workers could no longer ignore threats to workers, to the viability of organizations and, indeed, to the economy at large posed by the increasing prevalence of preventable chronic health conditions in the workforce. Coupled with this awareness is accumulating research that links many of these health conditions (e.g., obesity and Type II diabetes) to occupational exposures as well as to personal risk factors and illustrates the superiority of integrated prevention strategies for addressing these complementary risks.

With regard to these research developments, we now have a rather sophisticated understanding of how personal risk factors and occupational exposures act together to increase risk of injury and illness, thereby setting the stage for integrated interventions. As described in a recent report by Schulte and colleagues at $\mathrm{NIOSH}^{9)}$, personal and occupational risk factors may contribute directly and independently in an additive fashion to the same health or safety outcome. Interactive effects are also possible. As cited in the Schulte report, for example, obesity magnifies the influence of prolonged kneeling on the risk for osteoarthritis. In addition to direct and interactive effects, there is substantial evidence of an indirect pathway between occupational exposures and health outcomes that results from an effect of occupational exposures on personal risk factors. Effects of this nature are well established in the job stress and coping literature, and have been affirmed 
in recent, large scale European investigations that have linked workplace psychosocial stressors with physical inactivity, smoking intensity, the extremes of body mass index, and with both weight gain and loss ${ }^{10-12)}$.

This interplay of personal and occupational risk factors is of interest because of the implications for integrated interventions. Interactive effects of personal and occupational risk factors, for example, suggest the possibility for synergistic (interactive) effects of integrated interventions - a speculation that is sprinkled throughout the literature on integrated prevention strategies.

There has also been an accumulation, albeit incremental, in intervention studies favoring integrated prevention programs. Most prominent are the Harvard University WellWorks studies ${ }^{13,14)}$, which found positive effects of integrated (worksite health promotion plus occupational safety and health) interventions on dietary behaviors and smoking cessation in worker cohorts. These studies have appeared against a backdrop of increasing corporate reports of successful implementation of integrated worker health programs. More recently, for example, a considerably reduced mortality rate was observed in a decade-long follow-up of 7500 workers from a German chemical firm subsequent to the embedding of health promotion activities into an existing occupational medicine program ${ }^{15}$. Further evidence of the success of integrated interventions comes from the growing body of literature on health and productivity management ${ }^{16,17)}$.

Although results of this research have been encouraging, the knowledge base on the merits of integrated worker health interventions is still limited. A look at the peer-reviewed literature today will reveal that designed studies to examine either the efficacy or effectiveness of integrated worker health interventions are still scarce. Accounts of natural experiments or demonstrations from corporate interventions are often anecdotal and commonly lack sufficient specificity to fully understand the intervention manipulation or protocol.

In their 2003 report, Steps to a Healthier Workforce ${ }^{18)}$, Sorensen and Barbeau discuss knowledge gaps and future directions for research on the integration of worksite health programs. Recommendations include calls for the expansion of research in social epidemiology to better understand the etiology of occupational disease in general, methods development to support integration studies, further tests of the efficacy and effectiveness of integrated interventions, and additional attention to process evaluation and dissemination research. A decade later, the need to address the issues raised in this agenda has not diminished, and this rich discussion is recommended reading for investigators with interests in integration research. I conclude my comments with a technical note on an unresolved issue raised in this discussion - the potential for synergistic effects with integrative prevention strategies.

The expectation for synergism - that effects of integrated interventions may be greater than the sum of the effects of constituent interventions alone - is a recurrent but unstudied proposition in the literature, and investigation of this hypothesis seems long overdue. With respect to worksite health promotion and health protection, a test for synergism would require study designs that enable statistical analysis for interactive effects of these two interventions. However, integration studies have most commonly compared effects of some combination of worksite health promotion and health protection interventions with interventions involving health promotion or health protection alone, or a control with no intervention at all. Study designs of this nature do not allow for the detection of interactions and make it impossible to rule out more than additive (main) effects in the explanation of findings.

Taking this concern about study design a step further, questions about the incremental effects of integrated interventions relative to interventions that are comprehensive but not formally integrated are certainly of interest. Positive effects are apparent in the health and productivity management literature, which shows gains in health, safety, and performance outcomes following the implementation of cross-functional management systems to oversee corporate health and benefit programs ${ }^{16,17)}$. However, research designs that would enable better controlled evaluation of integrated interventions in comparison to interventions that are comprehensive, but operate parallel to one another, seem to be absent in the literature.

Setting aside the practical difficulties of experimental research in workplace settings, study designs that permit further investigation of integrated interventions along these lines would seem to be especially timely and important in strengthening the case for integrated prevention strategies.

In sum, integration of worksite health promotion and health protection activities is clearly emerging as a new paradigm for practice in occupational safety and health, and there is need for a more ambitious program of research to guide this practice. Hopefully the present comments will serve to draw greater international attention and research contributions to this fertile area of study. 


\section{References}

1) Hymel PA, Loeppke RR, Basse CM, Burton WM, Hartenbaum NP, Hudson W, McLellan RK, Mueller KL, Roberts MA, Yarborough CM, Konicki DL, Larson PW (2011) Workplace health protection and promotion: A new pathway for a healthier-and safer-workforce. J Occup Environ Med 53, 695-702. [Medline] [CrossRef]

2) DeJoy DM, Southern DJ (1993) An integrative perspective on work-site health promotion. J Occup Med 35, 1221-30. [Medline]

3) McLeroy KR, Bibeau D, Steckler A, Glanz K (1988) An ecological perspective on health promotion programs. Health Educ Q 15, 351-77. [Medline] [CrossRef]

4) Institute of Medicine (2005) Integrating Employee Health: A Model Program for NASA. The National Academies Press, Washington, DC.

5) Commission on Health and Safety and Workers Compensation (2010) The Whole Worker: Guidelines for Integrating Occupational Health and Safety with Workplace Wellness Programs. Commission on Health and Safety and Workers Compensation Oakland, CA.

6) McLellan D, Harden E, Markkanen P, Sorensen G (2002) SafeWell Practice Guidelines: An Integrated Approach to Worker Health Version 2.0. http://centerforworkhealth.sph. harvard.edu/images/stories/SafeWellPracticeGuidelines\&E xecSumm_Sept2012.pdf. Accessed October 15, 2013.

7) National Institute for Occupational Safety and Health. Total Worker Heath ${ }^{\mathrm{TM}}$. http://www.cdc.gov/niosh/TWH/default. html. Accessed October 15, 2013.

8) Schill AL, Chosewood LC () The NIOSH total Worker Health ${ }^{\mathrm{TM}}$ program: an overview. J Occup Environ Med (in press).

9) Schulte PA, Pandalai S, Wulsin V, HeeKyoung C (2012) Interaction of occupational and personal risk factors in workforce health and safety. Am J Public Health 102, 434-48. [Medline] [CrossRef]

10) Fransson EI, Keikkilä K, Nyberg ST, et al. (2012) Job strain as a risk factor for leisure-time physical inactivity: an individual participant meta-analysis of up to 170,000 men and women. Am J Epidemiol 176, 1078-89. [Medline] [CrossRef]

11) Heikkilä K, Nyberg ST, Fransson EI, et al. (2012) Job strain and tobacco smoking: An individual participant data meta-analysis of 166,130 adults in 15 European Studies. PLoS ONE 7,(7): e35463. [Medline] [CrossRef]

12) Nyberg ST, Heikkilä K, Fransson EI, et al. (2012) Job strain in relation to body mass index: Pooled analysis of 160,000 adults from 13 cohort studies. J Intern Med 272, 65-73. [Medline] [CrossRef]

13) Sorensen G, Stoddard A, Hunt MK, Hebert JR, Ockene JK, Avrunin-Spitz J, Himmelstein J, Hammond K (1998) The effects of a health promotion-health protection intervention on behavior change: the WellWorks study. Am J Public Health 88, 1685-90. [Medline] [CrossRef]

14) Sorensen G, Stoddard A, LaMontagne A, Emmons K, Hunt MK, Youngstrom R, McLellan D, Christiani DC (2002) A comprehensive worksite cancer prevention intervention: behavior change results from a randomized control trial. Cancer Causes Control 13, 493-502. [Medline] [CrossRef]

15) Ott MG, Young M, Zober A, Nasterlack M, Messerer P, Pluto RP, Lang S, Oberlinner C (2010) Impact of an occupational health promotion program on subsequent illness and mortality experience. Int Arch Occup Environ Health 83, 887-94. [Medline] [CrossRef]

16) Goetzel RZ (2012) Steps to a healthier workforce: integrating occupational health and safety and worksite health promotion: State of the science. In NIOSH Research Compendium: The NIOSH Total Worker Health ${ }^{\mathrm{TM}}$ Program: Seminal Research Papers 2012, 66-173. Department of Health and Human Services, DHHS (NIOSH) Publication No. 2012-146. http://www.cdc.gov/niosh/ docs/2012-146/pdfs/2012-146.pdf. Accessed October 15, 2013.

17) Bunn WB, Stave GM, Allen Naim AB (2010) Evidencebased benefit design: toward a sustainable health care future for employers. J Occup Environ Med 52, 956-63. [Medline] [CrossRef]

18) Sorensen G, Barbeau E (2012) Steps to a healthier workforce: integrating occupational health and safety and worksite health promotion: State of the science. In NIOSH Research Compendium: The NIOSH Total Worker Health $^{\mathrm{TM}}$ Program: Seminal Research Papers 2012, 1-65. Department of Health and Human Services, DHHS (NIOSH) Publication No. 2012-146. http://www.cdc.gov/niosh/ docs/2012-146/pdfs/2012-146.pdf.Accessed October 15, 2013.

Steven L. SAUTER Consultant to the NIOSH Total Worker Health Program, USA Associate Graduate Faculty, Northern Kentucky University, USA 